\title{
Effects of nivolumab in peritoneal carcinamatosis of malign melanoma in mouse model $^{1}$
}

\author{
Ozgul Duzgun', Inanc Samil Sarici", Serkan Gokcay"I', Kivilcim Eren Ates ${ }^{\prime \vee}$, Mehmet Bertan Yılmaz $^{\mathrm{V}}$
}

'MD, Department of Surgical Oncology, Umraniye Training and Research Hospital, Istanbul, Turkey. Conception, design, scientific, and intellectual content of the study; technical procedures.

"MD, Department of General Surgery, Kanuni Sultan Suleyman Training and Research Hospital, Istanbul, Turkey. Statistical analysis, manuscript writing, final approval.

I'MD, Department of Medical Oncology, Faculty of Medicine, Cukurova University, Adana, Turkey. Interpretation of data, critical revision.

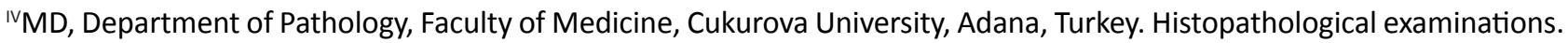
${ }^{v}$ Associate Professor, Department of Medical Biology, Faculty of Medicine, Cukurova University, Adana, Turkey. Critical revision.

\begin{abstract}
Purpose: To evaluate the efficacy of nivolumab and comparison with dacarbazine (DTIC) on peritoneal carcinomatosis of malignant melanoma in mouse model.

Methods: Mouse skin melanoma cells was injected under the capsule of the peritoneal surface in the left side of the abdomen. On postoperative day ten, mouses randomised into three groups. Group 1: Control, Group 2: HIPEC (Hyperthermic intraperitoneal chemotherapy) with DTIC and Group 3: HIPEC with Nivolumab. After the sacrification on postoperative day fifteen, peritoneum evaluated macroscopically and histopathologically by using peritoneal regression grading score (PRGS).

Results: In the 15th day exploration, all animals developed extensive intraperitoneal tumor growth in Group 1. In Group 2 and Group 3 median tumor size was $0.7 \pm 0.3 \mathrm{~cm}$ and $0.3 \pm 0.2 \mathrm{~cm}$ respectively ( $\mathrm{p}: 0.023)$. Peritoneal carcinomatosis index $(\mathrm{PCl})$ were significantly lower in Group 3 than other groups ( $p: 0.019)$. The lowest total tumor nodules in group 3 was $4 \pm 2$. The PGRS score was found significantly lower in Group 3 than other groups (p: 0.03). Lymphocytic response rate was found higher in the Group 3.

Conclusions: It has been found that nivolumab significantly better than DTIC on peritoneal metastases of malign melanoma in mouse models. Nivolumab treatment gives promising results with pathological evidence in the treatment of metastatic disease of malignant melanoma.
\end{abstract}

Key words: Dacarbazine. Melanoma. Carcinoma. Mice. 


\section{Introduction}

Malignant melanoma(MM) is a malignant neoplasm that arises from melanocyte and typically occur in the skin but may rarely occur in other locations and can give rise to primary melanoma in unexpected locations as peritoneum. It metastasizes to all organs of the body and often demonstrates unpredictable metastatic behavior. However, the prognosis of the patients with metastatic disease is dismal with a 5-year survival of less than $5 \%$, and a median survival duration of 6-9 months ${ }^{1-3}$. On the other hand the incidence of late recurrence of $\mathrm{MM}$ ranges from $0.98 \%$ to $6.7 \%$ of all cases ${ }^{1}$. Dacarbazine (DTIC) has been used as the standard of chemotherapy for metastatic melanoma for long since 1970s, and there are many studies of DTIC for advanced melanoma.

Advancesinunderstanding ofmelanoma biology, immunotherapy and target therapy (as Nivolumab), alone or in combination, have shown promising results in the treatment of advanced melanoma. Nivolumab is a human monoclonal antibody that blocks the interaction between programmed death1 (PD-1), programmed cell death ligand 1 ( PDL1) and programmed cell death ligand 2 (PDL2) and inhibits T cell proliferation and cytokine production. In recent years, nivolumab has been used in metastatic MM, non-small cell lung cancer, renal cell carcinoma, squamous cell carcinoma of the head and neck, Hodgkin's lymphoma and urothelial carcinoma. Additionaly, in 2017 National Comprehensive Cancer Network (NCCN) guideline, Nivolumab is used as a first line and second line treatment for inoperable or metastatic melanoma ${ }^{4,5}$. Nivolumab has never been used in peritoneal tumor involvement until now and the results of local applications in peritoneal cancers are not known. In our study, we tried to demonstrate the efficacy of nivolumab on peritoneal malignant melanoma cells in mouse models. Additionally, the effects of DTIC versus Nivolumab treatment on melanoma cells were also compared in this study,

\section{Methods}

This study was established at the Experimental Research Center of Cukurova University after obtaining the ethical committee approval of Cukurova University Medical Faculty (Approval number: 2015/10). Fourty five male Swiss Albino mouse, weighing 20-25g were used in the present study. The animals were maintained at $2 \circ \mathrm{C}$, humidity at $40-60 \%$ with a $12 \mathrm{hr}$ light/dark cycle and allowed free access to water and standard chow during the study. This research was carried out in accordance with the Guide for the Care and Use of Laboratory Animals (NIH, 1985).

\section{Preparation and application of melanoma cell culture}

Mouse skin melanoma cells (B16F10) were obtained from the Akdeniz University, Antalya, TURKEY. B16F10 cells were cultured in Dulbecco modified Eagle medium (DMEM; Gibco, New York, NY) supplemented with $10 \%$ fetal bovine serum (FBS; Gibco) and 1\% penicillin-streptomycin(Gibco). Experiments were conducted at passages 27 to 30 . At $70 \%$ confluency cells were trypsinized and suspended in medium to a concentration of $10^{6}$ cells $/ \mathrm{ml}$ for injections. After preperation melanoma cells mouses were anesthetized by intramuscular injection of ketamine $40 \mathrm{mg} / \mathrm{kg}$ (Ketalar;ParkeDavis, Eczacibasi, Istanbul,Turkey) and\%2 xylazinebio $8 \mathrm{mg} / \mathrm{kg}$ (Rometar; Bioveta ,Chech). A heating lamp was used to maintain the body temperature at $37.2^{\circ} \mathrm{C}$. Every efforts was made by the same surgeon with surgical technique due to ensure the standardization. After asepsi a $3 \mathrm{~cm}$ midline incision was made. The tumor cell suspension was injected under the capsule of the peritoneal surface in the left 
side of the abdomen. On postoperative day 10 mouses randomised into 3 groups with fifteen mouse in each group. group 1: control group 2: HIPEC with DTIC in a concentration of $15 \mathrm{mg} /$ $\mathrm{m}^{2}(\mathrm{n}=6)$, group 3: HIPEC with Nivolumab in a concentration of $10 \mathrm{mg} / \mathrm{m}^{2}$. HIPEC was applied with the open technique. The intraperitoneal temperature was maintained in $42^{\circ} \mathrm{C}$. Perfusion was performed over 30 minutes. The body surface of the animals was calculated with the Dubois Formula. After the perfusion the perfusate was removed and the abdomen was irrigated with saline for 10 minutes. Thereafter the abdomen was closed in one layer. On postoperative day 15 all animals were euthanized by cervical dislocation with overdose of $2 \mathrm{ml}$ pentobarbital sodium (175 $\mathrm{mg} / \mathrm{ml}$, KU Life, Copenhagen, Denmark). After the sacrification, the mouse fascia was opened abdominal cavity observed macroscopically.
Peritoneum dissecting carefully and added in $10 \%$ buffered formalin for histopathological analysis and tumor regression grading .

\section{Evaluation of peritoneal regression grading score}

The Peritoneal Regression Grading Score (PRGS) identifies four categories on the basis of the presence of residual tumor cells and the extent of regression features defined by Solass et al. ${ }^{6}$. PRGS 1 corresponds to a complete regression with absence of tumor cells; PRGS 2 to major regression features with only a few residual tumor cells; PRGS 3 to minor regression with predominance of residual tumor cells and only few regressive features; PRGS 4 to no response to therapy where the tumor cells are not accompanied by any regressive features (Chart 1 ).

Chart 1 - Definition of the peritoneal regression grading score (PRGS) according to Solass et al. ${ }^{6}$.

\begin{tabular}{lll}
\hline Grade & Tumor cells & Regression features \\
\hline PRGS 1- complete response & No tumor cells & $\begin{array}{l}\text { Abundant fibrosis and/or acellular mucin } \\
\text { pools and/or infarct-like necrosis }\end{array}$ \\
PRGS 2- major response & $\begin{array}{l}\text { Regressive changes } \\
\text { predominant over tumor } \\
\text { cells }\end{array}$ & $\begin{array}{l}\text { Fibrosis and/or acellular mucin pools and/or } \\
\text { infarct like necrosis predominant over tumor } \\
\text { cells }\end{array}$ \\
PRGS 3- minor response & $\begin{array}{l}\text { Predominance of tumor } \\
\text { cells }\end{array}$ & $\begin{array}{l}\text { Tumor cells predominant over fibrosis and/ } \\
\text { or acellular mucin pools and/or infarct-like } \\
\text { necrosis } \\
\text { No regressive changes }\end{array}$ \\
PRGS 4- no response & $\begin{array}{l}\text { Solid growth of tumor } \\
\text { cells (visible at lowest } \\
\text { magnification) }\end{array}$ & \\
\hline
\end{tabular}

"PRGS: Peritoneal Regression Grading Score

Statistical analysis

Statistical analyzes were done using Statistical Package for Social Sciences (SPSS) 16.0. Kruskal Wallis test was used in the comparison of the groups. The Mann-Whitney $U$ test was used to compare the four groups in the parameters where significant differences were found. $p<0.05$ was accepted as statistically significant. 


\section{- Results}

Two mice died in each Group 2 and Group 3 and 1 mouse died in Group 1 during the follow-up. These cases were excluded from the study. There is no significant difference in baseline weight values between the groups. Although the mean body weights were reduced in all groups during the study period, there was no statistical difference among the groups in terms of body weight changes. No local or systemic complications related to chemotherapeutic agent were observed.

In Group 1, small bowel metastases observed in 5 mouse and liver metastasis in 1 mouse. In Group 2 and 3, no metastasis was detected. In the 15th day exploration, all animals developed extensive intraperitoneal tumor growth in group 1 (Figure 1). Macroscopic and microscopic minor tumor implants were detected in Group 2 and pathologic complete response was seen in Group 3 (Figure 2). In group 3, the median tumor size was less than other groups. In group 2 and 3 median tumor size was $0.7 \pm 0.3 \mathrm{~cm}$ and $0.3 \pm 0.2 \mathrm{~cm}$ respectively (p: 0.023). PCl were significantly lower in group 3 than other groups ( $p: 0.019)$. The lowest total tumor nodules in group 3 were $4 \pm 2$. The PGRS score was found to be lower in the Nivolumab group than in the DTIC and control groups ( $p$ : 0.03). Lymphocytic response rate was found to be higher in the Nivolumab group than in the DTIC and control group (Table 1).
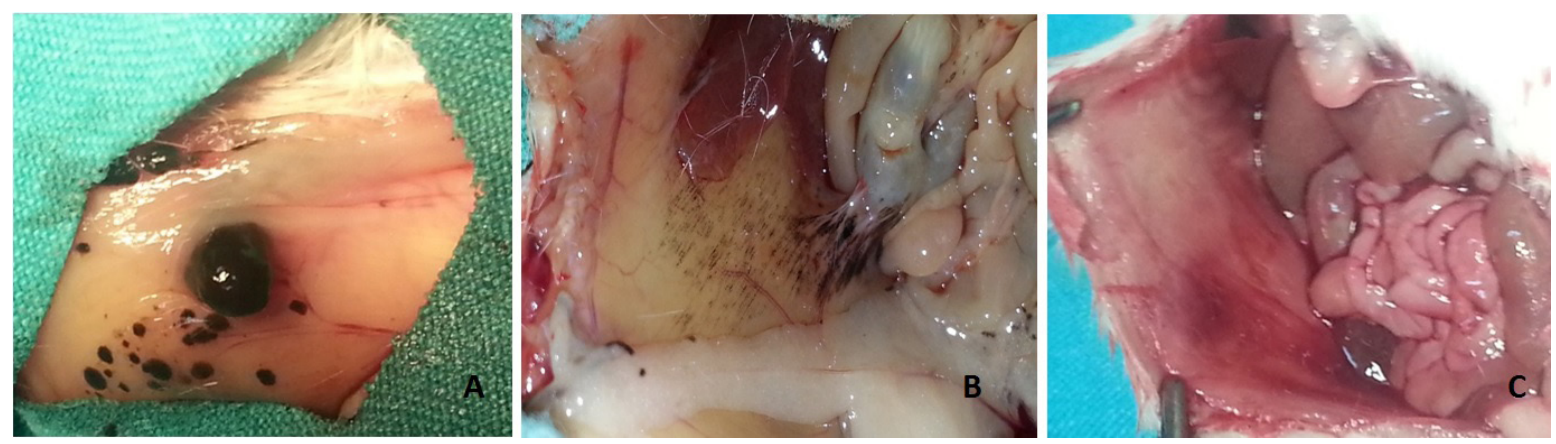

Figure 1 - Macroscopic views of each group after treatment. A. Control group: Solid growth of malign melanoma cells (visible at lowest magnification). B. Dacarbazine group: Limited tumor implantation. C. Nivolumab group: Complete response. No tumor cells.
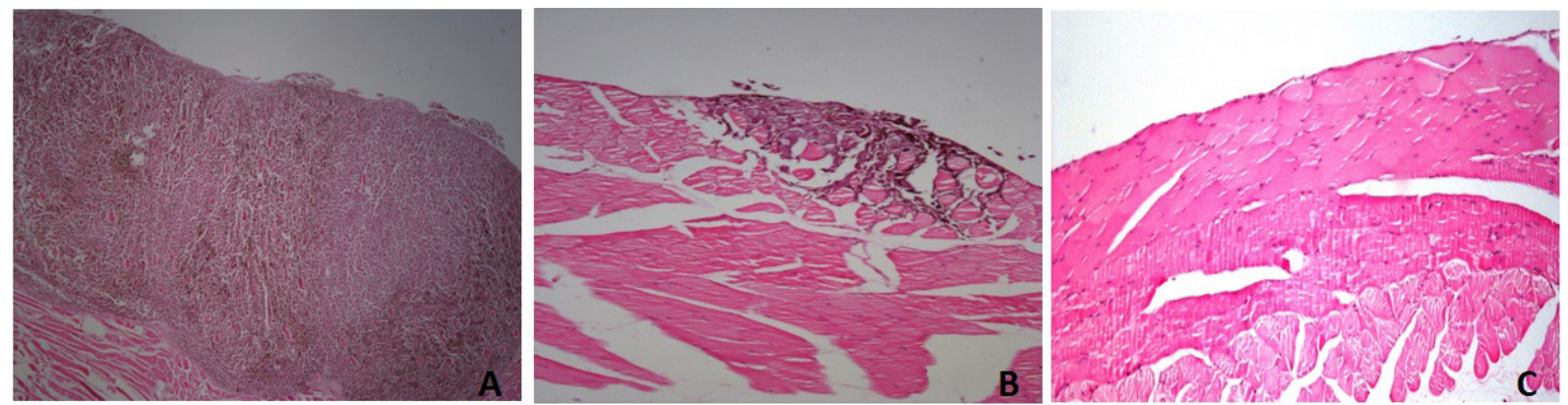

Figure $\mathbf{2}$ - Histologic response of each group after treatment. A. Control group: No regressive changes and histological response. B. Dacarbazine group: Tumor cells predominant over fibrosis with acellular mucin pools. C. Nivolumab group: Complete response. No tumor cells. 
Table 1 - Comparison of macroscopic and pathological responses between groups.

\begin{tabular}{lllll} 
Variables & $\begin{array}{l}\text { Group 1 } \\
\text { (Control) }\end{array}$ & $\begin{array}{l}\text { Group 2 } \\
\text { HIPEC }\end{array}$ & $\begin{array}{l}\text { (DTIC* } \\
\text { HIPEC }\end{array}$ & Proup 3 (Nivolumab+ \\
\hline Tumor size(cm) & $1.2 \pm 0.5$ & $0.7 \pm 0.3$ & $0.3 \pm 0.2$ & $\mathbf{0 . 0 2 3}$ \\
Total tumor nodules & $16 \pm 7$ & $9 \pm 4$ & $4 \pm 2$ & $\mathbf{0 . 0 0 1}$ \\
PCI $^{*}$ & 9 & 5 & 3 & $\mathbf{0 . 0 1 9}$ \\
PRGS $^{*}$ & $4 / 4$ & $3 / 4$ & $2 / 4$ & $\mathbf{0 . 0 3}$ \\
Lymphocytic response (\%) & 0 & 54 & 76 & $\mathbf{0 . 0 0 1}$ \\
\hline
\end{tabular}

"DTIC: Dacarbazine , HIPEC: Hyperthermic İntraperitoneal Chemotherapy, PCI: Peritoneal Carcinomatosis Index, PRGS: Peritoneal Regression Grading Score

\section{- Discussion}

Malignant melanoma is an aggressive and invasive cancer originating from melanocytes. The most dangerous aspect of melanoma is its ability, in later stages, to metastasize to other parts of the body. It effects many parts of region such as peritoneum, eyes, oropharengeal mucosa, gastrointestinal tracts,peritoneum, meninges, respiratory system and gynecological organs ${ }^{7}$. 5-year survival less than $5 \%$ patients with metastatic disease, and a median survival is 3-8 months $\mathrm{s}^{8-10}$. Melanoma cells resistant to chemotherapy, but DTIC is the standard chemotherapeutic agent for years with $15 \%$ avarage response and extend survival to 10 months ${ }^{11}$. Despite current NCCN guidelines, many oncology units still apply DTCl alone or combination with other agents in clinical practice ${ }^{12}$.

Due to advances in understanding of melanoma biology, immunotherapy and target therapy, new generation of chemotherapeutic agents that can directly affect cancer cells has begun to be used in treatment. Nivolumab is a human monoclonal antibody that blocks the interaction between PD-1, PD-L1 and PD-L2 ${ }^{13}$. Binding of these ligands to the PD-1 receptor found on T cells, inhibits T cell proliferation and cytokine production. Upregulation of the PD-1 ligands occurs in some tumors and signaling through this pathway can contribute to inhibition of active T-cell immune surveillance of tumors. According to the 2017 NCCN guidelines, Nivolumab is used as a first line and second line treatment for inoperable or metastatic melanoma. Nivolumab has never been used in peritoneal tumor involvement until now and the results of local applications in peritoneal cancers are not known.

Although nivolumab is recommended in the current treatment of $\mathrm{MM}$, recent controlled studies have shown that it is useful with prolong survival in advanced metastatic MM. Topalian et al. found median overall survival 16.8 months and 2-year overall survival rate $43 \%$ in advanced-stage malignant melanoma ${ }^{14}$. In another multicenter, randomized, controlled Phase III study, CheckMate 066, DTIC and Nivolumab compared in 418 untreated BRAF wild-type unresectable stage III or IV melanoma patients and 1 year overall survival rate in the Nivolumab and DTIC groups were $73 \%$ and $42 \%$, respectively ${ }^{4}$. Additionally, they found $7.6 \%$ complete responses with nivolumab and $1 \%$ in DTIC group. However, no study has been conducted on the efficacy of nivolumab in peritoneal carcinomatosis of MM. In this study, we obtained promising results with pathological evidence when applied Nivolumab in combination with cytoreductive surgery+HIPEC in the treatment of $\mathrm{MM}$ peritoneal spread in mouse. At the same time, comparison of DTIC and Nivolumab in the 
peritoneal spread of MM was also performed for the first time in this study.

Radiologic and histopathologic parameters is frequently used in clinical practice and researches to evaluate oncologic treatment responses. However, radiological evaluation especially in peritoneal malignancies is inadequate in showing and measuring tumor implants of $1 \mathrm{~cm}$ and smaller size. Therefore histopathological findings are more important in evaluating tumor regression. In the histopathological evaluation of tumor regression in abdminal malignancies, different evaluations (Mandard and Becker grading in upper gastrointestinal carcinomas, Dworak or the Rödel grading system for rectal cancer) have been used in previous studies although they are not specific for peritoneal carcinomatosis ${ }^{15,16}$. For this reason, a new standard sampling and histopathological classification system for peritoneal malignancies of Solas et al. was used in our study. In this study, tumor regression was defined in four groups and it was found to be very useful in the evaluation of peritoneal carcinamatosis. In our study, we found that the tumor regression score was significantly higher in the Nivolumab group than in the DTIC and control group. Additionally, Nivolumab group significantly better results from DTIC and control group according to the tumor size, $\mathrm{PCl}$ index and lymphocyte response.

\section{- Conclusions}

Nivolumab is significantly better than DTIC on peritoneal metastases of malign melanoma in mouse models. Nivolumab treatment gives promising results with pathological evidence in the treatment of metastatic disease of malignant melanoma.

\section{References}

1. Ahmed I. Malignant melanoma: prognostic indicators. Mayo Clin Proc. 1997;72(4):356-
61. PMID: 9121184.

2. Manola J, Atkins M, Ibrahim J, Kirkwood J. Prognostic factors in metastatic melanoma: a pooled analysis of Eastern Cooperative Oncology Group trials. J Clin Oncol. 2000;18(22):3782-93. PMID: 11078491.

3. Unger JM, Flaherty LE, Liu PY, Albain KS, Sondak VK. Gender and other survival predictors in patients with metastatic melanoma on Southwest Oncology Group trials. Cancer. 2001;91(6):1148-55. PMID: 11267960.

4. Robert C, Long GV, Brady B, Dutriaux C, Maio M, Mortier L, Hassel JC, Rutkowski P, McNeil C, Kalinka-Warzocha E, Savage KJ, Hernberg MM, Lebbé C, Charles J, Mihalcioiu C, Chiarion-Sileni V, Mauch C, Cognetti $F$, Arance A, Schmidt $H$, Schadendorf D, Gogas $H$, Lundgren-Eriksson L, Horak C, Sharkey B, Waxman IM, Atkinson V, Ascierto PA. Nivolumab in previously untreated melanoma without BRAF mutation. N Engl J Med. 2015;372(4):320-30. PMID: 25399552.

5. Weber JS, D'Angelo SP, Minor D, Hodi FS, Gutzmer R, Neyns B, Hoeller C, Khushalani $\mathrm{NI}$, Miller WH Jr, Lao CD, Linette GP, Thomas L, Lorigan $\mathrm{P}$, Grossmann KF, Hassel JC, Maio M, Sznol M, Ascierto PA, Mohr P, Chmielowski B, Bryce A, Svane IM, Grob JJ, Krackhardt AM, Horak C, Lambert A, Yang AS, Larkin J. Nivolumab versus chemotherapy in patients with advanced melanoma who progressed after anti-CTLA-4 treatment (CheckMate 037): a randomised, controlled, open-label, phase 3 trial. Lancet Oncol. 2015;16(4):37584. PMID: 25795410.

6. Solass W, Sempoux C, Detlefsen S, Carr NJ, Bibeau F. Peritoneal sampling and histological assessmentof therapeutic response in peritoneal metastasis:proposal of the Peritoneal Regression Grading Score (PRGS). Pleura Peritoneum. 2016;2(1):65116. doi: 10.1515/pp-2016-0011.

7. Iijima S, Oka K, Sasaki M, Tateishi Y, Saito $H$, Sandoh $N$, Nihei T, Kawano $H$, Kawasaki T, Hakozaki $H$, Mori N. Primary jejunal malignant melanoma first noticed because of the presence of parotid lymph node metastasis. J Am Acad Dermatol. 2003;49(2):319-23. PMID: 12894088.

8. Larsen AK, Jensen MB, Krag C. Longterm survival after metastatic childhood melanoma. Plast Reconstr Surg Glob Open. 
20149;2(6):163. PMID: 25289356.

9. Hodi FS, O'Day SJ, McDermott DF, Weber RW, Sosman JA, Haanen JB, Gonzalez R, Robert C, Schadendorf D, Hassel JC, Akerley W, van den Eertwegh AJ, Lutzky J, Lorigan P, Vaubel JM, Linette GP, Hogg D, Ottensmeier $\mathrm{CH}$, Lebbé C, Peschel C, Quirt I, Clark JI, Wolchok JD, Weber JS, Tian J, Yellin MJ, Nichol GM, Hoos A, Urba WJ. Improved survival with ipilimumab in patients with metastatic melanoma. N Engl J Med. 2010;363(8):71123. PMID: 20525992.

10.Avril MF, Aamdal S, Grob JJ, Hauschild A, Mohr P, Bonerandi JJ, Weichenthal M, Neuber K, Bieber T, Gilde K, Guillem Porta V, Fra J, Bonneterre J, Saïag P, Kamanabrou $D$, Pehamberger $H$, Sufliarsky J, Gonzalez Larriba JL, Scherrer A, Menu Y. Fotemustine compared with dacarbazine in patients with disseminated malignant melanoma. J Clin Oncol. 2004;22(6):1118-25. PMID: 15020614.

11.Yang AS, Chapman PB. The history and future of chemotherapy for melanoma. Hematol Oncol Clin North Am. 2009;23(3):583-97. PMID: 19464604.

12.Eggermont AM, Kirkwood JM. Re-evaluating the role of dacarbazine in metastatic melanoma: what have we learned in 30 years? Eur J Cancer. 2004;40(12):1825-36. PMID: 15288283.

13.Oláh J. Advances in immunotherapy for metastatic melanoma. Magy Onkol. 2017 6;61(2):132-6. PMID: 28585614.

14. Topalian SL, Sznol M, McDermott DF, Kluger HM, Carvajal RD, Sharfman WH, Brahmer JR, Lawrence DP, Atkins MB, Powderly JD, Leming PD, Lipson EJ, Puzanov I, Smith DC, Taube JM, Wigginton JM, Kollia GD, Gupta A, Pardoll DM, Sosman JA, Hodi FS. Survival, durable tumor remission, and long-term safety in patients with advanced melanoma receiving nivolumab. J Clin Oncol. 2014;32(10):1020-30. PMID: 24590637.

15. Thies S, Langer R. Tumor regression grading of gastrointestinal carcinomas after neoadjuvant treatment. Front Oncol. 2013;3:262. doi: 10.3389/fonc.2013.00262.

16. McCoy MJ, Hemmings C, Hillery S, Penter C, Bulsara MK, Zeps N, Platell CF. Neoadjuvant chemoradiotherapy for rectal cancer: how important is tumour regression? ANZ J Surg. 2015 Dec 3. doi: 10.1111/ans.13394. [Epub ahead of print].

\section{Correspondence:}

Inanc Samil Sarici

Bahçeşehir 1. kısım mahallesi Ispartakule Cad-

desi Kiptaş Vaditepe 4

Bölge Sitesi K1 Blok Daire:16 Başakşehir

İstanbul Turkey

Phone: +9005532271140

issarici2015@gmail.com

Received: Aug 18, 2017

Review: Oct 16, 2017

Accepted: Nov 19, 2017
Conflict of interest: none

Financial source: none 